Ульяна Сересова

\title{
ИДЕИ ГОСУДАРСТВЕННОЙ СОСТОЯТЕЛЬНОСТИ И СТРЕССОУСТОЙЧИВОСТИ В ПУБЛИЧНОЙ ПОЛИТИКЕ: ВОЗВРАЩЕНИЕ ГОСУДАРСТВА
}

\author{
Crowley K., Stewart J., Kay A., Head B.W. (eds.) (2020) \\ Reconsidering Policy: Complexity, Governance and the State. \\ Bristol: Policy Press, 2020. 242 p. ISBN 978-1-4473-3311-1.
}

DOI: $10.17323 / 727-0634-2021-19-3-542-546$

Основной посыл монографии «Переосмыслить социальную политику» в том, что необходимо вернуть государство в предметное поле публичной политики. В центре внимания авторов- категории state capacity, resilience и governance как инструменты анализа публичной политики. Первая категория только недавно вошла в академический лексикон, поэтому исследователи по-разному её концептуализируют. В самом широком смысле её можно рассматривать как дееспособность государства. Авторами она интерпретируется как «набор компетенций и возможностей, необходимых для выполнения государством его ключевых функций; комбинация умений и ресурсов, необходимых для формулирования политического выбора, реализации стратегического курса, оценивания преимуществ и недостатков возможных политических реформ, а также способности исследовать процесс публичной политики» (P. XIII). Государственная дееспособность должна обеспечивать resilience, т.е. возможность государства сопротивляться кризисам (стихийным бедствиям, экономическим рецессиям, террористическим атакам, военным действиям). Она позволяет «сформулировать новые роли», переформатировать публичную политику, восстановить легитимность государственной власти (Р. 58). Инновации, возникающие в публичной политике как ответ на кризисные явления, реализуются разными акторами, но управляются государством как ведущим политическим субъектом (Р. 73).

Концепция governance- последняя базовая категория монографии, которая может переводиться как «руководство», «правление» или «управление». Она предполагает множественное и сложное взаимодействие различных государственных и негосударственных организаций и политических

\footnotetext{
Ульяна Игоревна Сересова-к.полит.н., доцент, кафедра социально-гуманитарных наук, сервиса и культурного наследия, Государственное бюджетное образовательное учреждение высшего образования Московской области «Академия социального управления», Мытищи, Россия. Электронная почта: seresova_ui@asou-mo.ru
} 
институтов, объединенных в политические сети, возникающие в ходе реализации политических реформ (Р. 45). Государственная власть в эпоху governance деконцентрируется и «размазывается» между государственными, благотворительными и коммерческими организациями, сплетенными в сложные и запутанные социальные сети (Р. 61). В свою очередь это приводит к тому, что государство с классическими контрольно-командными практиками управления, становящимися менее актуальными, пропадает из сферы академического интереса. В книге приводится понятие metagovernance, объясняющее ведущую роль государства как координатора деятельности политических сетей. Если прочие субъекты политических сетей- общественные и коммерческие организации- берут на себя отдельные функции государства, то за государством все равно остается ряд полномочий, которые эти акторы на себя взять не могут. К таковым можно отнести «формулирование правил игры», установление и поддержание политико-административных границ, политические коммуникации с общностью, перераспределение экономических ресурсов, выполнение функции арбитра в случае конфликта между акторами политических сетей (Р. 61-63).

В социальной политике на перекрестке идей governance, resilience и state capacity находятся классические вопросы социальной защиты и социального обеспечения наиболее уязвимых слоев населения, живущих на грани или за гранью социальной эксклюзии (см.: Mares 2005; Lee 2009; Duckett, Hussain 2008). Авторы монографии поэтапно рассматривают, как меняется понимание политической повестки дня, политических институтов и систем публичной политики, переосмысляется государство и его границы, работа консультационных органов, реализация политических реформ, осуществление политических изменений. Циклическая структура монографии напоминает классическую структуру теории политического цикла- традиционного исследовательского инструмента публичной политики, состоящего из шести этапов: идентификация социально-политической проблемы, формирование на ее основе политической повестки дня, формулирование различных вариантов решения проблемы, легализация и легитимация одного из вариантов через законодательство, реализация политической реформы, оценка ее эффективности. Этап оценки эффективности- замыкающий этап политического цикла позволяет снова сформулировать проблему и снова внести ее в политическую повестку дня.

Идеи государственной состоятельности и стрессоустойчивости относительно недавно вошли в лексикон отечественной политической науки. Они используются в рамках компаративной политологии и теории международных отношений, т.е. вне предметного поля публичной и социальной политики (Ахременко и др. 2019; Горельский, Миронюк 2019; Коцур 2019; Трещенков 2018). В отличие от state capacity, категория governance pocсийскими исследователями активно используется как в рамках публичной политики (Сморгунов 2018), так и в пределах теорий государственного 
управления (Барабашев 2016) и концепций политической модернизации (Гельман 2019), но не служит «оптическим инструментом» для анализа социальной политики. Изучение этих проблем в России осуществляется, преимущественно, в рамках различных социологических и экономических парадигм. Политологические контексты социальной политики, теории публичной политики применительно к вопросам социальной защиты остаются за пределами внимания российских политологов (напр., Тарасенко, Кулмала 2016).

Таким образом, теории публичной политики, и, в частности концепции governance, state capacity и resilience являются перспективным инструментом анализа российской социальной политики. С помощью этого инструмента можно проводить сравнительные исследования, операционализируя концепты через статистические показатели. Продуктивно рассматривать отдельные кейсы- конкретные социальные реформы, направленные на борьбу с бедностью, социальной эксклюзией, безработицей, акцентируя внимание на функциях государства и деятельности всех негосударственных акторов, объединенных в политические сети. Так, например, борьба с коронавирусом, включающая профилактику, организацию лечебной работы, меры социальной поддержки, организацию работы волонтеров, - тот самый пример, когда концепты governance, state capacity и resilience могут оказаться полезными как в теоретическом исследовании, так и в оценке практики публичного управления.

\section{Список источников}

Ахременко А.С., Горельский И.Е., Мельвиль А. Ю. (2019) Как и зачем измерять и сравнивать государственную состоятельность разных стран мира? Полис. Политические исследования, (2): 8-23.

Барабашев А.Г. (2016) Кризис государственного управления и его влияние на основные административные парадигмы государства и бюрократии. Bonpocbl государственного и муниципального управления, (3): 163-194.

Гельман В.Я. (2019)«Недостойное правление»: политика в современной России. СПб.: Изд-во Европейского университета в Санкт-Петербурге.

Горельский И.Е., Миронюк М.Г. (2019) Взбираясь по «статусной лестнице»: опыт эмпирического исследования связи статуса государства в системе международных отношений и государственной состоятельности. Политическая наука, (3): 140-174.

Коцур Г.В. (2019) Возникновение стрессоустойчивого субъекта: кризисное взаимодействие государства и общества. Вестник Санкт-Петербургского университета. Международные отношения, 12 (1):93-112.

Сморгунов Л.В. (ред.) (2018) Публичная политика: институты, ијифровизация, развитие. М.: Аспект-Пресс. 
Тарасенко А. В., Кулмала М. (2016) Представительство интересов и социальная политика в России: ветеранские организации как посредники между обществом и государством. Журнал исследований соџиальной политики, 14 (4): 551-568.

Трещенков Е.Ю. (2018) Стрессоустойчивость в современных дискурсах управления. Власть, (8): 24-31.

Duckett J., Hussain A. (2008) Tackling Unemployment in China: State Capacity and Governance Issues. The Pacific Review, 21 (2):211-229.

Lee J. (2009) Developmentalism, Social Welfare and State Capacity in East Asia: Integrating Housing and Social Security in Singapore. Journal of Asian Public Policy, 2 (2): 157-170.

Mares I. (2005) Social Protection around the World: External Insecurity, State Capacity, and Domestic Political Cleavages. Comparative Political Studies, 38 (6): 623-651.

Uliana Seresova

STATE CAPACITY AND RESILIENCE IN PUBLIC POLICY:
BRINGING THE STATE BACK IN

Crowley K., Stewart J., Kay A., Head B.W. (eds.) (2020) Reconsidering Policy: Complexity, Governance and the State. Bristol: Policy Press, 2020. 242 p. ISBN 978-1-4473-3311-1.

DOI: 10.17323/727-0634-2021-19-3-542-546

\section{References}

Akhremenko A. S., Gorelskiy I.E., Melville A. Yu. (2019) Kak i zachem izmeryat' i sravnivat' gosudarstvennuyu sostoyatel'nost' raznykh stran mira? [How and Why should We Measure and Compare State Capacity of Different Countries? Theoretical and Methodological Foundations]. Polis. Politicheskie issledovaniya [Polis. Political Studies], (2): 8-23.

Barabashev A. G. (2016) Krizis gosudarstvennogo upravleniya i ego vliyanie na osnovnye administrativnye paradigmy gosudarstva i byurokratii [Crisis of State Governance and Its Influence on Basic Administrative Paradigms of State and Bureaucracy]. Voprosy gosudarstvennogo i munitsipal'nogo upravleniya [Public Administration Issues], (3): 163-194.

Duckett J., Hussain A. (2008) Tackling Unemployment in China: State Capacity and Governance Issues. The Pacific Review, 21 (2):211-229.

Gelman V. Ya. (2019) 'Nedostoynoe pravlenie': politika v sovremennoy Rossii [The Politics of Bad Governance in Contemporary Russia]. St. Petersburg: EUSP Press.

Gorelskiy I.E., Mironyuk M. G. (2019) Vzbirayas' po 'statusnoy lestnitse': opyt empiricheskogo issledovaniya svyazi statusa gosudarstva $\mathrm{v}$ sisteme mezhdunarodnykh otnosheniy

Uliana Seresova - Cand. Sci. (Polit.), Department of Social Sciences and Humanities, Service and Cultural Heritage, Academy of Social Management, Moscow region, Mytischi, Russian Federation. Email: seresova_ui@asou-mo.ru 
i gosudarstvennoy sostoyatel'nosti [Climbing the Status Ladder: An Experiment in Empirical Research of Relation Between Status of a State in the System of International Relations and State Capacity]. Politicheskaya nauka [Political Science], (3): 140-174.

Kotsur G. V. (2019) Vozniknovenie stressoustoychivogo sub"ekta: krizisnoe vzaimodeystvie gosudarstva i obshchestva [The Emergence of the Resilient Subject: Crisis Interaction Between State and Society]. Vestnik Sankt-Peterburgskogo universiteta. Mezhdunarodnye otnosheniya [Vestnik of Saint Petersburg University. International Relations], 12 (1): 93-112.

Lee J. (2009) Developmentalism, Social Welfare and State Capacity in East Asia: Integrating Housing and Social Security in Singapore. Journal of Asian Public Policy, 2 (2): 157-170.

Mares I. (2005) Social Protection around the World: External Insecurity, State Capacity, and Domestic Political Cleavages. Comparative Political Studies, 38 (6): 623-651.

Smorgunov L. V. (ed.) (2018) Publichnaya politika: instituty, tsifrovizatsiya, razvitie [Public Policy: Institutions, Digitalisation, Development]. Moscow: Aspekt-Press.

Tarasenko A. V., Kulmala M. (2016) Predstavitel'stvo interesov i sotsial'naya politika v Rossii: veteranskie organizatsii kak posredniki mezhdu obshchestvom i gosudarstvom [Representing Interests and the Crafting Of Social Policy: Viewing Russian Veterans' Organisations as Brokers between State and Society]. Zhurnal Issledovanii Sotsial'noi Politiki [The Journal of Social Policy Studies], 14 (4):551-568.

Treshchenkov E. Yu. (2018) Stressoustoychivost' v sovremennykh diskursakh upravleniya [Resilience in Contemporary Governance Discourses]. Vlast' [The Authority], (8):24-31. 